\title{
Sistem Pakar Berbasis Web untuk Mendiagnosa Penyakit Hewan Ternak Ruminansia Besar
}

\author{
(Web-based Expert System for Diagnosing Livestock Animal Large Ruminants) \\ Deila Etha Pritia, Ario Yudo Husodo, Moh.Ali Albar \\ Program Studi Teknik Informatika, Fakultas Teknik, Universitas Mataram \\ J1. Majapahit 62, Mataram, Lombok NTB, INDONESIA \\ Email: deilaethap@gmail.com, ario@unram.ac.id,mohalialbar@unram.ac.id
}

\begin{abstract}
Ruminant animals was a group of mammals that chew the cud or eat the food there was swallowed. In Sumbawa district, there was 10 ruminant livestock diseases that are often infected by anthrax, brucellosis, snoring or septichaemia epizootica (SE), mucus or bovine epheral fever (BEF), surra worm or thelazia, scabies and abdominal bloating. One of the obstacles in order to increase the productivity of livestock was the existence of various diseases there was any effect on the life of livestock. This system aimed to make it easier for farmers to obtained information about diseases in their animals.

System tested methods used to test this system was black box testing, system accuracy tested with expert, questionnaire and precision and recall accuracy tested, black box test results show all existing functions was running well. testing between the system with the expert obtained an accuracy of 93\%. Testing questionnaire got result of conformity assessment system to user requirement or breeder with answer agreed equal to $62.68 \%$. The testing of precision and recall obtained the result of precision testing of $95.5 \%$ and recall of $8.3 \%$, So it can be concluded that this system was in accordance with the needs of users.
\end{abstract}

Key words: Large Ruminant, Expert System, Web, Similarity

\section{PENDAHULUAN}

Hewan ternak ruminansia merupakan kelompok hewan mamalia yang memamah biak atau memakan kembali makanan yang telah ditelannya [1]. Hewan ternak ruminansia dibagi menjadi dua kelompok yaitu ruminansia besar dan ruminansia kecil. Hewan ternak ruminansia besar terdiri dari sapi dan kerbau. Pada Kabupaten Sumbawa terdapat 10 penyakit hewan ternak ruminansia yang sering terjangkit yaitu Anthrax, Brucellosis, Ngorok atau Septichaemia Epizootica (SE), Ingusan atau Malignant Catrrahal Fever (MFC), Penyakit Mulut dan Kuku (PKM), Demam tiga hari atau
Bovine Epheral Fever (BEF), Surra, Cacing mata atau Thelazia, Scabies, dan Kembung Perut.

Salah satu hambatan dalam rangka meningkatkan produktivitas ternak yaitu adanya berbagai penyakit yang sangat berpengaruh terhadap kehidupan ternak. Terjangkitnya penyakit pada hewan ternak akan membuat peternak mengalami kerugian ekonomi yang cukup tinggi karena kurangnya informasi dan pengetahuan tentang masalah penyakit yang tibatiba menyerang hewan ternaknya sehingga membuat hewan ternak bisa mati mendadak. Terlebih lagi jika itu dialami oleh peternak di pedesaan terpencil. Kurangnya tenaga dokter hewan dan mahalnya biaya yang dikeluarkan peternak untuk membayar dokter membuat penanganan terhadap hewan ternak menjadi lambat.

Untuk memudahkan peternak memperoleh informasi mengenai penyakit pada hewan ternaknya, perlu dibuatkan suatu sistem aplikasi pakar berbasis web untuk mengaplikasikan pengetahuan pakar ke dalam suatu sistem sehingga peternak tidak perlu mendatangkan dokter hewan untuk melihat kondisi ternaknya dan dengan sendirinya mengecek kondisi dengan sistem tersebut, hal ini akan memudahkan dalam proses mendiagnosa penyakit dari hewan ternaknya melalui sistem pakar berbasis website sehingga dapat diakses kapanpun dan dimanapun.

Dalam membangun sistem pakar penyakit hewan ternak ruminansia ini digunakan perhitungan similarity yaitu untuk mencari kasus dengan menghitung kedekatan antara kasus baru dengan kasus lama berdasarkan pada pencocokan masing-masing bobot yang diberikan oleh pakar dengan probabilitas kemungkinan gejala untuk setiap penyakitnya. Sistem pakar berbasis web untuk mendiagnosa penyakit hewan ternak ruminansia besar ini diharapkan dapat membantu peternak dalam mendapatkan informasi seputar penyakit yang menyerang hewan ternaknya sehingga dapat mencegah sedini mungkin dengan dilakukan diagnosa, pengobatan, pengendalian, bahkan pencegahan secara cepat dan tepat. 


\section{TINJAUAN PUSTAKA}

Penelitian pertama sebagai rujukan yaitu "Sistem Pakar Untuk Diagnosis Awal Penyakit Pada Hewan Potong Dengan Menggunakan Teorema Bayes". Penelitian ini menghasilkan sistem pakar yang dapat mendiagnosis penyakit pada hewan potong. Sistem ini dirancang menggunakan Teorema Bayes untuk melakukan penalaran pada gejala penyakit dalam basis pengetahuan dan menggunakan teknik forward chaining untuk menelusuri basis pengetahuan. Pada penelitian ini data yang digunakan sebanyak 24 penyakit. Pengujian antara sistem dengan pakar memiliki akurasi kecocokan sebesar 80\% [2].

Penelitian yang berjudul "Identifikasi Penyakit Sapi Pada Sapi Ternak dengan Forward Chaining", menghasilkan sistem pakar yang dapat mengidentifikasi penyakit pada sapi ternak. Pada penelitian ini data yang digunakan sebanyak sembilan penyakit dengan menggunakan metode Forward Chaining. Pengujian antara sistem dengan pakar memiliki akurasi kecocokan sebesar 60\% [3].

Penelitian yang berjudul "Penerapan Case-Based Reasoning Pada Sistem Cerdas Untuk Pendeteksian dan Penanganan Dini Penyakit Sapi", menggunakan metode berbasis Case-Based Reasoning. Pada penelitian ini pengujian dilakukan menggunakan tiga skenario dengan menggunakan masing-masing 20 data uji dari case memory, diluar case memory, dan data yang memiliki kemiripan gejala parsial dari case memory. Skenario 1 mendapatkan akurasi sebesar $100 \%$, skenario 2 sebesar $71.25 \%$, dan skenario 3 sebesar $97.5 \%$ [4].

Penelitian yang berjudul "Penerapan Algoritma KNN (Nearest Neighbor) Untuk Deteksi Penyakit (Kanker Serviks)". Data penelitian yang digunakan pada penelitian tersebut sebanyak sembilan penyakit. Sistem pakar ini menggunakan algoritma K-NN (Nearest Neighbor) [5].

\section{METODE PERANCANGAN}

Flowchart dari sistem yang akan dibuat dapat dilihat pada Gambar 1.

\section{A. Perancangan Usecase Diagram}

Tahap ini merupakan perancangan usecase yang menggambarkan proses yang dapat dilakukan oleh pengguna sistem ini. Perancangan usecase dilakukan agar para pengguna mengetahui proses-proses apa saja yang dapat dilakukan di dalam sistem ini. Perancangan usecase dapat dilihat pada Gambar 2.

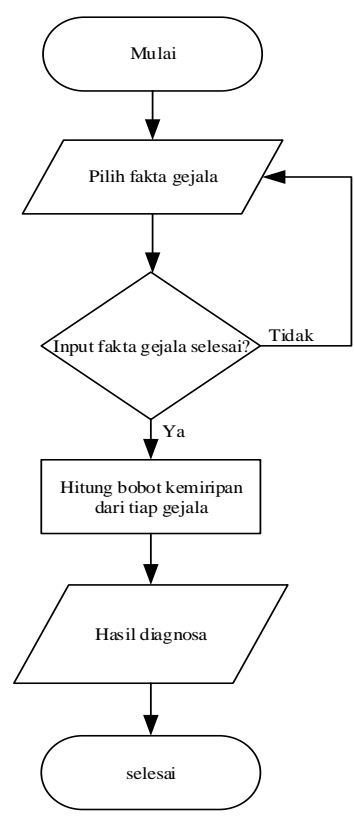

Gambar 1 Flowchart Pengembangan Sistem

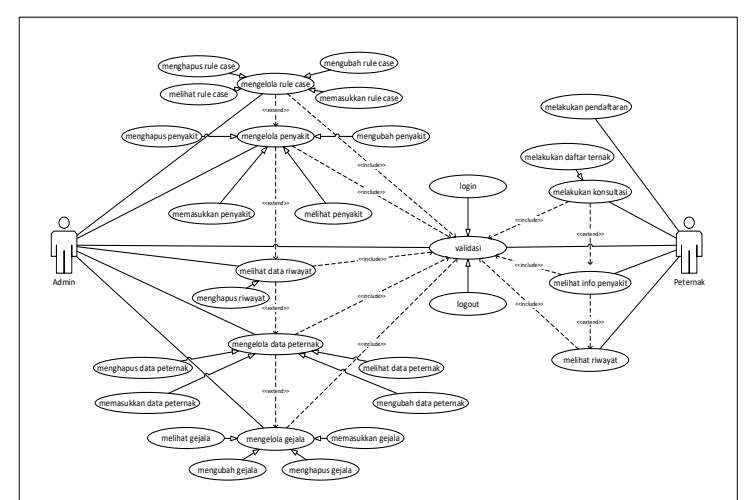

Gambar 2 Perancangan Usecase Sistem

\section{B. Perancangan Entity Relational Diagram}

Tahap ini merupakan tahap perancangan database dimana, data-data yang ada pada sistem ini seluruhnya akan disimpan dalam satu database, sehingga data menjadi terintegrasi. Perancangan database sistem dapat dilihat pada Gambar 3.

\section{Perancangan Class Diagram}

Tahap ini merupakan tahap perancangan class diagram dimana, data-data yang ada pada sistem ini seluruhnya akan disimpan dalam satu database, sehingga data menjadi terintegrasi. Perancangan database sistem dapat dilihat pada Gambar 4. 


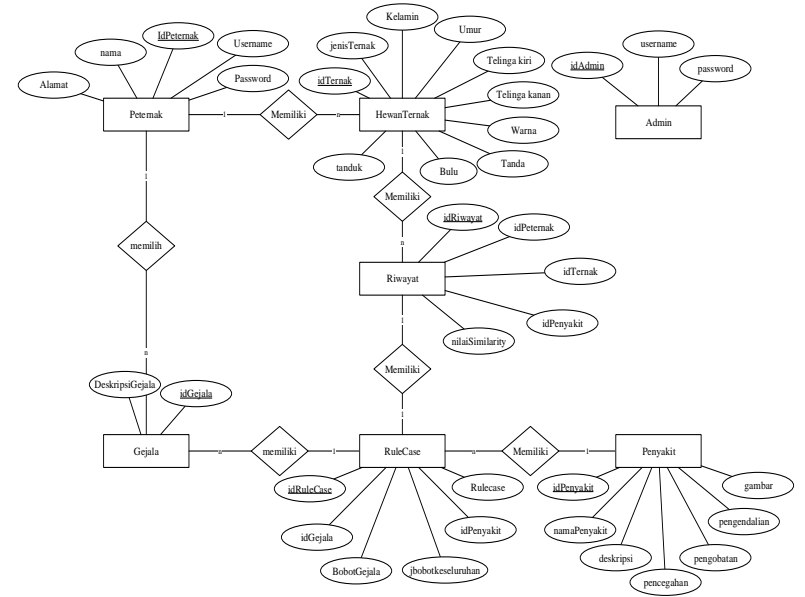

Gambar 3 Entity Relational Diagram Sistem

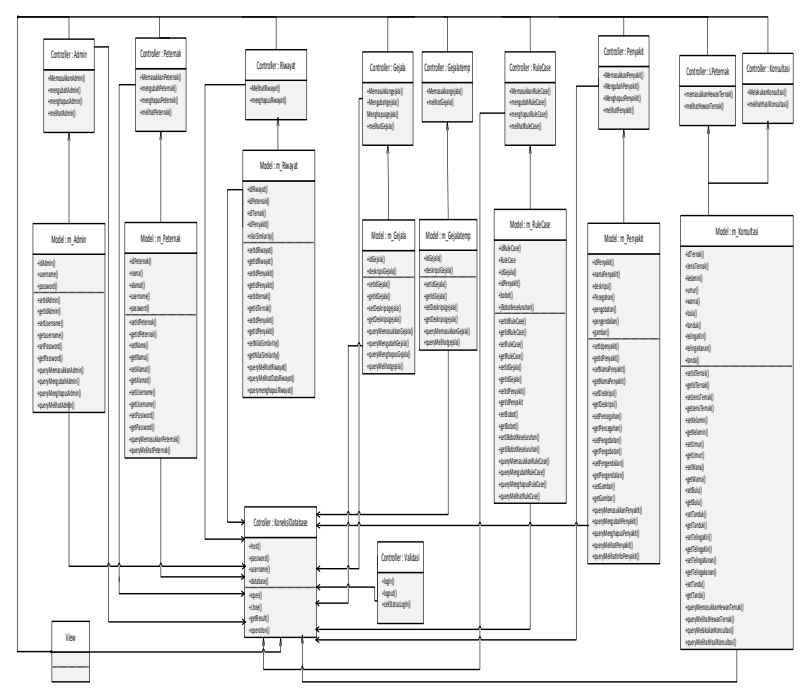

Gambar 4 Class Diagram Sistem

\section{HASIL DAN IMPLEMENTASI}

\section{A. Implementasi Interface}

Pada implementasi sistem terdapat beberapa tampilan interface sistem berdasarkan pengguna sistem ini yang terdiri dari peternak dan admin. Berikut hasil dari implementasi interface dapat dilihat pada Gambar 5, Gambar 6, dan Gambar 7.

Gambar 5 merupakan halaman utama dari pada sistem. Fungsi halaman ini yaitu menjelaskan secara singkat tentang sisitem pakar penyakit hewan ternak ruminansia besar. Gambar 6 merupakan tampilan halaman peternak saat melakukan konsultasi, dimana terdapat gejala-gejala yang akan dipilih sesuai dengan yang diderita ternaknya. Gambar 7 merupakan tampilan hasil dari diagnosa sistem yang telah dilakukan oleh peternak. Terdapat 2 penyakit yang nilai kemiripannya mendekati.

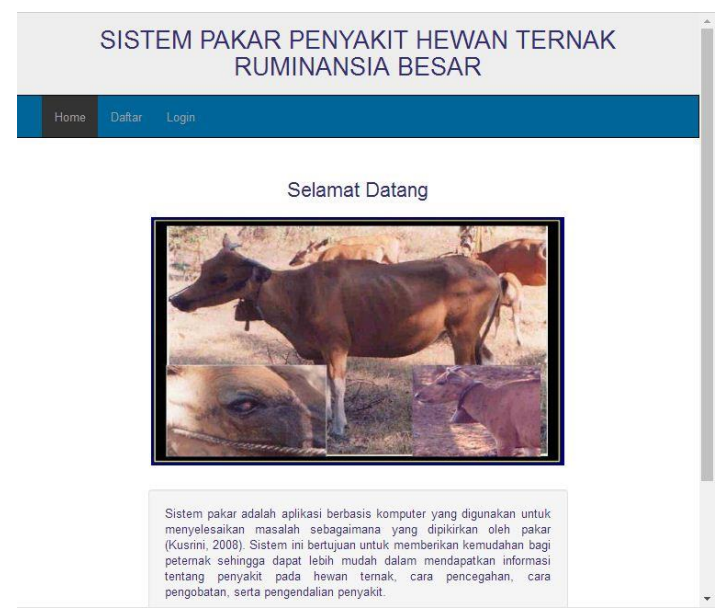

Gambar 5 Halaman Utama

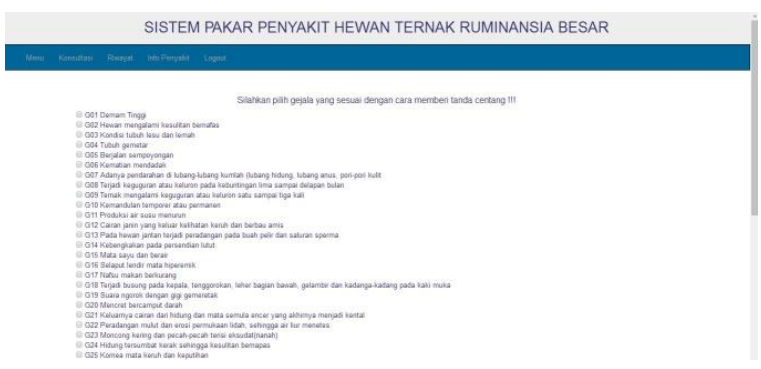

Gambar 6 Halaman Konsultasi Sistem

SISTEM PAKAR PENYAKIT HEWAN TERNAK RUMINANSIA BESAR

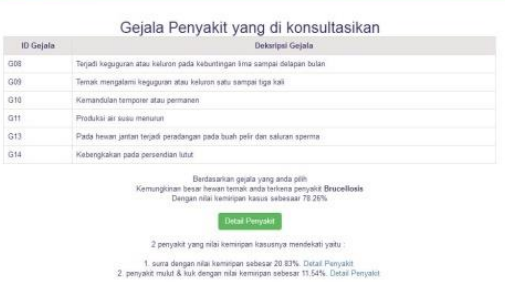

Gambar 7 Halaman Hasil Konsultasi Sistem

\section{B. Pengujian Sistem}

\section{B.1. Pengujian Akurasi Sistem dan Pakar}

Pengujian akurasi antara sistem dengan pakar adalah untuk mengetahui seberapa besar kecocokan dari hasil uji coba antara sistem dengan pakar. Pada pengujian ini terdapat dua pakar sebagai pengujinya. Tabel I menunjukkan perbandingan akurasi sistem dengan pakar. 
TABEL I. PERBANDINGAN AKURASI SISTEM DENGAN PAKAR

\begin{tabular}{|c|c|c|c|c|}
\hline \multirow[b]{2}{*}{ No } & \multicolumn{3}{|c|}{ Presentasi } & \multirow[t]{2}{*}{ Ket } \\
\hline & Aplikasi & Pakar 1 & Pakar 2 & \\
\hline 1 & $\begin{array}{l}\text { Anthrax } \\
(80.95 \%)\end{array}$ & Anthrax & Anthrax & Valid \\
\hline 2 & $\begin{array}{l}\text { Anthrax } \\
(61.9 \%)\end{array}$ & Anthrax & Anthrax & Valid \\
\hline 3 & $\begin{array}{c}\text { Ngorok } \\
(79.31 \%)\end{array}$ & Ngorok & Ngorok & Valid \\
\hline 4 & $\begin{array}{c}\text { Ingusan } \\
(88.89 \%)\end{array}$ & Ingusan & Ingusan & Valid \\
\hline 5 & $\begin{array}{c}\text { Penyakit } \\
\text { mulut dan } \\
\text { kuku (96.15 } \\
\%)\end{array}$ & $\begin{array}{l}\text { Penyakit } \\
\text { mulut dan } \\
\text { kuku }\end{array}$ & $\begin{array}{l}\text { Penyakit } \\
\text { mulut dan } \\
\text { kuku }\end{array}$ & Valid \\
\hline 6 & $\begin{array}{c}\text { Scabies } \\
(86.61 \%)\end{array}$ & Scabies & Scabies & Valid \\
\hline 7 & $\begin{array}{c}\text { Penyakit } \\
\text { mulut dan } \\
\text { kuku (61.54 } \\
\%)\end{array}$ & $\begin{array}{c}\text { Penyakit } \\
\text { mulut dan } \\
\text { kuku }\end{array}$ & $\begin{array}{c}\text { Penyakit } \\
\text { mulut dan } \\
\text { kuku }\end{array}$ & Valid \\
\hline 8 & $\begin{array}{c}\text { Ngorok } \\
(79.31 \%)\end{array}$ & Ngorok & Ngorok & Valid \\
\hline 9 & $\begin{array}{l}\text { Ngorok } \\
(58.62 \%)\end{array}$ & Ngorok & Ngorok & Valid \\
\hline 10 & $\begin{array}{c}\text { Demam } 3 \\
\text { Hari } \\
(88.46 \%) \\
\end{array}$ & Demam 3 Hari & Demam 3 Hari & Valid \\
\hline 11 & $\begin{array}{c}\text { Kembung } \\
\text { Perut } \\
(76.19 \%)\end{array}$ & $\begin{array}{l}\text { Kembung } \\
\text { Perut }\end{array}$ & $\begin{array}{l}\text { Kembung } \\
\text { Perut }\end{array}$ & Valid \\
\hline 12 & $\begin{array}{l}\text { Anthrax } \\
(61.9 \%)\end{array}$ & Anthrax & Anthrax & Valid \\
\hline 13 & $\begin{array}{l}\text { Anthrax } \\
(100 \%)\end{array}$ & Anthrax & Anthrax & Valid \\
\hline 14 & $\begin{array}{c}\text { Surra } \\
(87.5 \%)\end{array}$ & Surra & Surra & Valid \\
\hline 15 & $\begin{array}{c}\text { Surra } \\
(45.83 \%)\end{array}$ & Anthrax & Anthrax & $\begin{array}{l}\text { Tidak } \\
\text { Valid }\end{array}$ \\
\hline 16 & $\begin{array}{c}\text { Cacing } \\
\text { mata } \\
(95.24 \%)\end{array}$ & Cacing mata & Cacing mata & Valid \\
\hline 17 & $\begin{array}{l}\text { Brucellosis } \\
(82.61 \%)\end{array}$ & Brucellosis & Brucellosis & Valid \\
\hline 18 & $\begin{array}{c}\text { Ngorok } \\
(55.17 \%)\end{array}$ & Ngorok & Ngorok & Valid \\
\hline 19 & $\begin{array}{c}\text { Penyakit } \\
\text { mulut dan } \\
\text { kuku } \\
(61.54 \%)\end{array}$ & $\begin{array}{l}\text { Penyakit } \\
\text { mulut dan } \\
\text { kuku }\end{array}$ & $\begin{array}{l}\text { Penyakit } \\
\text { mulut dan } \\
\text { kuku }\end{array}$ & Valid \\
\hline 20 & $\begin{array}{c}\text { Surra } \\
(95.83 \%)\end{array}$ & Surra & Surra & Valid \\
\hline 21 & $\begin{array}{l}\text { Ingusan } \\
(77.78 \%)\end{array}$ & Ingusan & Ingusan & Valid \\
\hline 22 & $\begin{array}{c}\text { Penyakit } \\
\text { mulut \& } \\
\text { kuku } \\
(69.23 \%)\end{array}$ & $\begin{array}{c}\text { Penyakit } \\
\text { mulut \& kuku }\end{array}$ & $\begin{array}{c}\text { Penyakit } \\
\text { mulut \& kuku }\end{array}$ & Valid \\
\hline 23 & $\begin{array}{l}\text { Scabies } \\
(78.26 \%)\end{array}$ & Scabies & Scabies & Valid \\
\hline 24 & $\begin{array}{c}\text { Ngorok } \\
(93.1 \%)\end{array}$ & Ngorok & Ngorok & Valid \\
\hline 25 & $\begin{array}{c}\text { Demam } 3 \\
\text { hari } \\
(76.92 \%) \\
\end{array}$ & Demam 3 hari & Demam 3 hari & Valid \\
\hline
\end{tabular}

\begin{tabular}{|c|c|c|c|c|}
\hline 26 & $\begin{array}{c}\text { Cacing } \\
\text { Mata } \\
(80.95 \%)\end{array}$ & Cacing Mata & Cacing Mata & Valid \\
\hline 27 & $\begin{array}{c}\text { Anthrax } \\
(61.9 \%)\end{array}$ & Anthrax & Ngorok & $\begin{array}{c}\text { Tidak } \\
\text { Valid }\end{array}$ \\
\hline 28 & $\begin{array}{c}\text { Ngorok } \\
(68.97 \%)\end{array}$ & Ngorok & Ngorok & Valid \\
\hline 29 & $\begin{array}{c}\text { Surra } \\
(95.83 \%)\end{array}$ & Surra & Surra & Valid \\
\hline 30 & $\begin{array}{c}\text { Ingusan } \\
(70.73 \%)\end{array}$ & Ingusan & Ingusan & Valid \\
\hline
\end{tabular}

Nilai akurasi sistem $=($ Jumlah data tepat $/$ Jumlah seluruh data) $* 100 \%$

$$
\begin{aligned}
& =(28 / 30) * 100 \% \\
& =0.93 * 100 \% \\
& =93 \%
\end{aligned}
$$

Dari perhitungan diatas dapat diketahui nilai akurasi dari pengujian antara sistem dengan pakar yaitu sebesar 93\%.

\section{B.2. Pengujian Kuesioner}

Pengujian dengan menggunakan kuesioner dilakukan dengan mencari responden untuk mencoba menjalankan sistem, kemudian diberikan pertanyaanpertanyaan mengenai kualitas dari sistem yang telah dibuat dilihat dari sisi pengguna. Kuesioner diberikan kepada 30 responden sebagai pengguna sistem.

Daftar pertanyaan yang diberikan untuk useradalah sebagai berikut:

1. Desain interface dari sistem ini cukup menarik?

2. Sistem dapat menampilkan hasil yang jelas?

3. Sistem ini dapat memberikan informasi tentang penyakit hewan ternak ruminansia besar seperti pengobatan, pencegahan, dan pengendalian?

4. Sistem ini mudah digunakan ?

5. Sistem ini dapat digunakan untuk mendiagnosa penyakit hewan ternak ruminansia besar.

Dari pertanyaan tersebut, responden diminta untuk menjawab dengan nilai - nilai tertentu, diantaranya:

- $1=$ Sangat tidak setuju (STS).

- 2 = Tidak setuju(TS).

- 3 = Tidak tahu(TT).

- $4=\operatorname{Setuju}(\mathrm{S})$.

- 5 = Sangat setuju(SS).

Berdasarkan jawaban kuesioner, langkah selanjutnya adalah menghitung persentase dari setiap jawaban yang diberikan oleh pengguna di setiap pertanyaan. Berdasarkan data hasil kuesioner, dapat dicari persentase masing-masing jawaban dengan menggunakan persamaan 1 .

$$
Y=\frac{P}{Q} * 100 \%
$$


Dimana:

$\mathrm{P}=$ Banyaknya jawaban tiap pertanyaan

$\mathrm{Q}=$ Jumlah responden

$\mathrm{Y}=$ Nilai persentase

Untuk menghitung persentase rata-rata nilai dari setiap poin jawaban, perhitungan digunakan perhitungan seperti pada persamaan 2 sebagai berikut.

Rata - rata $=$

$\frac{\text { Persentase jawaban ke-1+....+Persentase jawaban ke-5 }}{5}$

Dengan persamaan 2 persentase responden terhadap jawaban kuesioner yang terdiri dari lima jawaban dapat dihitung secara keseluruhan dengan didefinisikan sebagai nilai rata-rata.

Hasil rekapitulasi data kuesioner dan persentase jawaban pengguna pada setiap pertanyaan yang telah dihitung dengan menggunakan persamaan 1 dijabarkan pada Tabel II.

TABEL II. HASIL PENGUJIAN KUESIONER

\begin{tabular}{|c|c|c|}
\hline No & Keterangan & $\%$ \\
\hline 1 & $\begin{array}{c}\mathrm{STS}=0, \mathrm{TS}=0, \mathrm{TT}=5, \mathrm{~S}=15, \mathrm{SS} \\
=10\end{array}$ & 83.3 \\
\hline 2 & $\begin{array}{c}\mathrm{STS}=0, \mathrm{TS}=0, \mathrm{TT}=1, \mathrm{~S}=20, \mathrm{SS} \\
=29\end{array}$ & 96.7 \\
\hline 3 & $\begin{array}{c}\mathrm{STS}=0, \mathrm{TS}=0, \mathrm{TT}=4, \mathrm{~S}=18, \mathrm{SS} \\
=8\end{array}$ & 86.7 \\
\hline 4 & $\begin{array}{c}\mathrm{STS}=0, \mathrm{TS}=0, \mathrm{TT}=3, \mathrm{~S}=21, \mathrm{SS} \\
=6\end{array}$ & 90 \\
\hline 5 & $\begin{array}{c}\mathrm{STS}=0, \mathrm{TS}=0, \mathrm{TT}=6, \mathrm{~S}=20, \mathrm{SS} \\
=4\end{array}$ & 80 \\
\hline $\begin{array}{l}\text { rata- } \\
\text { rata }\end{array}$ & $\begin{array}{c}\mathrm{STS}=0, \mathrm{TS}=0, \mathrm{TT}=12.66 \\
\mathrm{~S}=62.68, \mathrm{SS}=24.66\end{array}$ & \\
\hline
\end{tabular}

Berdasarkan hasil pengujian kuesioner yang dilakukan dapat didisimpulkan bahwa :

1. untuk semua pertanyaan nomor 1, responden mendukung bahwa interface sudah menarik dengan persentase sebesar $83.3 \%$.

2. Untuk pertanyaan nomor 2 , responden mendukung bahwa sistem dapat menampilkan hasil yang jelas dengan persentase sebesar $96.7 \%$.

3. Untuk pertanyaan nomor 3 , responden mendukung bahwa Sistem ini dapat memberikan informasi tentang penyakit hewan ternak ruminansia besar dengan persentase sebesar $86.7 \%$.

4. Untuk pertanyaan nomor 4 , responden mendukung bahwa Sistem ini mudah digunakan dengan persentase sebesar $90 \%$.

5. Untuk pertanyaan nomor 5, responden mendukung bahwa Sistem ini dapat digunakan untuk mendiagnosa penyakit hewan ternak ruminansia besar dengan persentase sebesar $80 \%$.

Hasil dari perhitungan rata-rata keseluruhan jawaban responden terhadap pertanyaan didapatkan nilai $0 \%$ untuk jawaban sangat tidak setuju dan tidak setuju dikarenakan tidak ada responden yang memilih point 1 dan 2 yaitu sangat tidak setuju dan setuju, untuk jawaban tidak tahu sebesar $12.66 \%$, untuk jawaban setuju sebesar $62.68 \%$ dan untuk jawaban sangat setuju sebesar $24.66 \%$.

Sehingga dapat disimpulkan bahwa responden pengguna sistem pakar untuk mendiagnosa penyakit hewan ternak ruminansia besar setuju bahwa desain interface sistem cukup menarik, sistem dapat menampilkan hasil yang jelas, sistem dapat memberikan informasi tentang penyakit hewan ternak ruminansia besar, sistem mudah digunakan, dan sistem dapat digunakan untuk mendiagnosa penyakit dengan persentase sebesar $62.68 \%$.

\section{B.3. Pengujian Akurasi Precision Recall}

Berdasarkan hasil pengujian terhadap 30 data, terdapat 28 data yang teridentifikasi terkena penyakit oleh pakar dan sistem. Dalam melakukan pengujian terhadap sistem dan pakar didapatkan hasil precision dan recall yang akan diuji dengan persamaan sebagai berikut.

1. True positive (TP) : Kelas yang diprediksi positif terkena penyakit oleh sistem dan benar menurut pakar

2. True negative (TN) : Kelas yang diprediksi negatif terkena penyakit oleh sistem dan benar menurut pakar

3. False Positive (FP) : Kelas yang diprediksi positif terkena penyakit oleh sistem dan salah menurut pakar

4. False Negative (FN) : Kelas yang diprediksi negatif terkena penyakit oleh sistem dan salah menurut pakar

Untuk menghitung nilai precision diberikan rumus sebagai berikut :

1. Precision recall terhadap penyakit Anthrax:

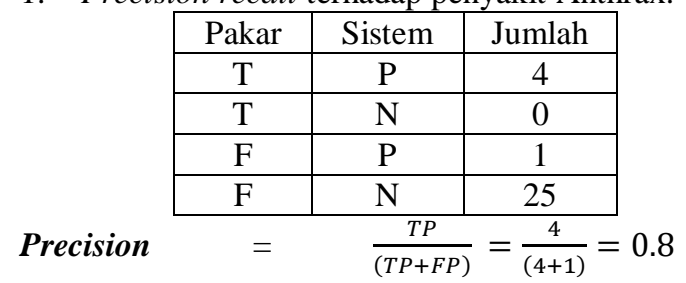

Recall $=\frac{T P}{(T P+F N)}=\frac{4}{(4+25)}=0.13$ 
2. Precision recall terhadap penyakit Ngorok:

\begin{tabular}{|c|c|c|}
\hline Pakar & Sistem & Jumlah \\
\hline $\mathrm{T}$ & $\mathrm{P}$ & 5 \\
\hline $\mathrm{T}$ & $\mathrm{N}$ & 0 \\
\hline $\mathrm{F}$ & $\mathrm{P}$ & 0 \\
\hline $\mathrm{F}$ & $\mathrm{N}$ & 25 \\
\hline \multicolumn{2}{|c|}{$\frac{T P}{(T P+F P)}=\frac{5}{(5+0)}=1$}
\end{tabular}

Recall $=\frac{T P}{(T P+F N)}=\frac{5}{(5+25)}=0.16$

Terdapat 10 perhitungan precision dan recall tiap peynyakit. Sehingga dari perhitungan tersebut, di dapatkan average dari precision recall .

\section{Average Precision}

$$
\begin{aligned}
& =\frac{\text { Precision } P 01+\text { Precision } P 02+\cdots+\text { precision } N}{\text { total Precision }} \\
& =\frac{0.8+1+1+1+1+1+1+0.75+1+1}{(10)}=0.955
\end{aligned}
$$

\section{Average Recall}

$$
\begin{aligned}
& =\frac{\text { RecallP01+RecallP } 02+\cdots+\text { RecallN }}{\text { total } R e c a l l}= \\
& \text { total Recall }
\end{aligned}
$$

$$
\text { (10) }
$$

$=0.083$

Dari perhitungan di atas, didapatkan nilai precision sebanyak $95.5 \%$ dan recall sebanyak $8.3 \%$.

\section{KESIMPULAN DAN SARAN}

\section{A. Kesimpulan}

Berdasarkan hasil penelitian yang telah dilakukan dapat ditarik beberapa kesimpulan yaitu sebagai berikut :

1. Sistem Pakar berbasis web untuk mendiagnosa penyakit hewan ternak ruminansia besar dapat digunakan untuk membantu pengguna mencari informasi mengenai penyakit hewan ternak ruminansia besar berupa deskripsi penyakit, pengobatan penyakit, pencegahan penyakit, dan pengendalian penyakit.

2. Sistem Pakar berbasis web untuk mendiagnosa penyakit hewan ternak ruminansia besar dapat digunakan untuk mengetahui seberapa besar persentase dan jenis penyakit yang terjangkit di Kabupaten Sumbawa Besar dengan melihat data riwayat yang tertera.

3. Hasil pengujian antara sistem dengan pakar didapatkan bahwa sistem Pakar berbasis web untuk mendiagnosa penyakit hewan ternak ruminansia besar dapat berjalan sesuai dengan yang diharapkan dan memiliki tingkat akurasi sebesar 93\%.

4. Pengujian pada Precision memiliki tingkat akurasi sebesar $95.5 \%$ dan Recall memiliki tingkat akurasi sebesar $8.3 \%$.

5. Pengujian kuesioner memiliki persentase sebesar $62.68 \%$ menyatakan setuju dengan sistem pakar penyakit hewan ternak ruminansia besar.

\section{B. Saran}

Dalam pengembangan aplikasi sistem pakar berbasis web untuk mendiagnosa penyakit hewan ternak ruminansia besar, terdapat beberapa saran agar sistem ini menjadi lebih baik antara lain:

1. Untuk pengembangan sistem ini dapat ditambahkan fitur-fitur lainnya seperti manage data admin, verifikasi password pada saat melakukan pendaftaran agar lebih aman, upload foto hewan yang terkena penyakit, dan lain sebagainya yang dapat membangun sistem lebih baik.

2. Sistem pakar berbasis web untuk mendiagnosa penyakit hewan ternak ruminansia besar dapat dikembangkan dengan menggunakan metode yang berbeda seperti K-Nearest Neighbor atau mengkombinasikan 2 metode.

3. Untuk pengembangan selanjutnya, pakar berbasis web untuk mendiagnosa penyakit hewan ternak ruminansia besar dapat diterapkan pada platform lainnya seperti Android dan IOS.

\section{DAFTAR PUSTAKA}

[1] Sudjadi, B., dan Laila, S., 2006, Biologi Sains dalam kehidupan $2 B$ Semester Kedua, Yudhistira, Jakarta (Ebook).

[2] Agustian, F.A., 2013, Sistem Pakar untuk Diagnosis Awal Penyakit Hewan potong dengan Menggunakan Teorema Bayes, Fakultas Sains dan Teknologi, Universitas Islam Negeri Sultan Syarif Kasim Riau, Pekanbaru.

[3] Masa, A.F., dan Buditjahjanto, I.G.P.A 2012,Identifikasi Penyakit Sapi Pada Sapi Ternak dengan Forward Chaining, Fakultas Teknik, Universitas Negeri Surabaya, Surabaya.

[4] Prakoso, I.B., Anggraeni, W., dan Mukhlason, A., 2012, Penerapan Cased-Based Reasoning Pada Sistem Cerdas Untuk Pendeteksian dan Penanganan Dini Penyakit Sapi, Fakultas Teknologi Informasi, Institut Sepuluh Nopember (ITS), Surabaya.

[5] Mariana, N., Redjeki, R.S., dan Razaq, J.A., 2015, Penerapan Algoritma $k$-NN(Nearest Neighbor) untuk Deteksi Penyakit (Kanker Serviks), Universitas Stikubank Semarang, Semarang. 